\title{
Research on the Prevention and Control of Supply Chain Financial Risks from the Perspective of Enterprise Financing
}

\author{
Jianxiong Liu*
}

Canvard College, Beijing Technology and Business University, Hengshui 053000, Hebei province, China. E-mail: 1240726646@qq.com

\begin{abstract}
At present, China's economy is developing rapidly and all companies actively participate in market competition. Hence, many small-sized companies with lower competitiveness face more risks and may be shut down if no efficient marketing strategies are adopted. Among their obstacles, financing problems seriously affects the company's development. However, in view of the fierce market competition, emerging supply chain financing models has been constructed, which is highly valued by many companies. In addition, the supply chain financing mode has a positive impact on the development of enterprises. In this thesis, the corporate financing and its application in risk management will be analyzed in detail, so as to provide companies with better financial services and to ensure their stable and sustainable development.
\end{abstract}

Keywords: Supply Chain Finance; Financing Method; Development Bottleneck

\section{Introduction}

Generally speaking, the financial services provided by financial institutions to individual enterprises in the same industrial chain are called supply chain finance. In brief, businesses related to industry chains are allowed to supply chain finance to obtain financial services. Therefore, if all enterprises in the supply chain want to achieve coordinated development, they all need supply chain finance to obtain corresponding financial support. Only in this way can the whole supply chain can develop rapidly. Therefore, the enterprises that depend on the same supply chain could obtain mutual profits and develop faster through collaboration. Due to the current development of network technology, this new technology is widely used in the field of supply chain finance. It greatly improved the applicability of the supply chain financial model to corporate financing ${ }^{[1]}$.Meanwhile, Chinese banks and relevant government departments have made great contributions to the development of supply chain finance. Through the implementation of relevant documents and the establishment of financing platforms, the problem of corporate financing difficulties can be effectively resolved. Therefore, in this thesis, the following issues will be analyzed, including the financing difficulties in the application of supply chain finance, and proposed relevant countermeasures and suggestions to prevent the risks in the financing process, so as to enable enterprises to achieve healthy and sustainable development.

\section{Significance of supply chain financing}

\subsection{Alleviating the phenomenon of bank information asymmetry}

On the one hand, in the face of the emergence of the supply chain financial model, companies are changed from an

\footnotetext{
Copyright (C) 2021 Jianxiong Liu

doi: 10.18686/fm.v6i1.3263

This is an open-access article distributed under the terms of the Creative Commons Attribution Non-Commercial License

(http://creativecommons.org/licenses/by-nc/4.0/), which permits unrestricted non-commercial use, distribution, and reproduction in any medium, provided the original work is properly cited.
} 
independent business entity to a part of the supply chain. This shows that the business development of such enterprises has an important impact on the development of the whole supply chain. However, the financing of enterprises was restricted by the relevant requirements of banks, which makes it difficult to raise funds. An important reason for that restriction is that banks pay more attention to the operational risks of such enterprises. Nevertheless, the current supply chain finance model allows banks to control the financing risks of the entire supply chain to effectively reduce the risks from independent corporate financing because there is no obstacle to the online communication between the companies in the supply chain ${ }^{[2]}$.

On the other hand, the enterprises in the supply chain finance model get rid of the shackles of independent operation because of the protection of the entire supply chain, which guarantees the business goals of all enterprises in the entire supply should be reached. In addition, the supply chain provides strong support and helps with the establishment of an advantageous operating environment that accelerates its sales, so that companies ensures their own development in a longer period, so as to ensure the development of their companies as they expect. This can also help companies to accurately predict the financial risks that may arise during the development.

\subsection{Revitalizing the current assets and improve production turnover efficiency}

Based on the supply chain financial model, companies can use working capital to improve their own production and operation conditions so the possible problems caused by bank loans can be avoided. To compensate for the shortage of funds in production and operation, a pledge of movable property is provided for the bank, and the compensation is obtained. This is also why the company shortens the sales cycle through the supporting logistics and warehousing service provided by the logistics company, thus accelerating the return on capital and further improving the business efficiency of the company.

\subsection{Reduce bank credit risk and operating costs}

In the previous financing mode, the financing subject of bank credit was usually an independent financing subject. Therefore, it is necessary to understand adequate details about the financing enterprise's relevant conditions before the bank provides financing services, including production and operation conditions, financial conditions and mortgage, the value of real estate and third-party guarantee methods. The reason why those details are important is that banks need to solve the problem of information asymmetry between enterprises through in-depth understanding of the above content and information, so as to provide financing services for enterprises. However, it is normally time-consuming and expensive to acquire this information because of the rapid financing needs of enterprises. The emergence of current supply chain financing is an efficient way to solve this problem, because companies with supply chain guarantees share credit with core companies, so that banks will only focus on core companies and integrate core companies ${ }^{[3]}$. The overall situation enables banks to control the financing risks that may arise and provide corresponding financing services for financing enterprises. In addition, the trade between core enterprises and enterprises is also well controlled due to the close cooperation between banks and third-party logistics enterprises, which facilitates banks' monitoring and control of the corporate mortgage financing of movable assets. In short, under the mode of supply chain finance, the risks and operating costs of bank loan have been effectively guaranteed.

\section{Risks of supply chain finance}

\subsection{Alienation among enterprises in Chinese supply chain and Poor Management}

If a company fails to establish cooperative relationship with core companies in the supply chain, and the employees are not unified, the possible reason is the lack of close trade relations among the companies in the whole supply chain. It is often difficult to explain why the financing mechanism of supply chain finance is difficult to be established because the core enterprise has not included the enterprise in its own supply chain management system. This leads to a loose supply chain, which makes it difficult to develop stably. As a result, if commercial banks provide supply chain financial services, their risks and costs will increase and unnecessary losses may occur. At present, the supply 
chain management level of most domestic enterprises is not high, and only a few enterprises attach great importance to the coordination and management of the industrial chain. This makes it impossible for most companies to develop in a stable supply chain, making it difficult for banks to develop supply chain financial services.

\subsection{Defective risk control system of commercial banks for supply chain financing}

To develop a supply chain financial model, commercial banks need to frequently communicate with each client for information sharing, and to establish close cooperative relationship with third-party logistics companies. The company's risk control could be guaranteed to be efficient. Such control is crucial for the development of an enterprise because the increase of participants in supply chain finance of banks makes the financing service more and more complicated. In addition, due to the complexity of supply chain finance business and frequent operations, commercial banks have not formed a complete risk control system. Therefore, the risk control of commercial banks is not as effective as it should be.

\subsection{Low percentage of digital device applied into supply chain finance business}

For the conversion of credit risk into operational risk, the supply chain business can be developed into an online business, so that operational risks can be effectively controlled through electronic information technology, which has a positive effect on reducing risk exposure and also reduce the operational costs. However, as far as current electronic information technology and e-commerce are concerned, due to their relatively backward development, commercial banks still use manual operating systems for business processing, which cannot effectively improve the efficiency of bank operations and management. At the same time, this will also increase the risk and easily cause heavy losses.

\subsection{Lack of a legal system specifically for supply chain finance}

The diversification of the participants makes the application of the law complicated, because the number of participants in the supply chain financing model keeps increasing. Not only banks, enterprises, core enterprises, but also third-party logistics companies have joined that supply chain financing. There is no strict control of the institutions to participate in such a model and there are no comprehensive laws and regulations to effectively limit and manage some business processes. Hence, commercial banks face higher legal risks when developing supply chain financial finance services. That will do harm to the steady development of business. In addition, due to the lack of complete laws and regulations, the moral hazard among supply chain entities is increasing. That will negatively affect the sustainable development of an enterprise.

\section{Financing Management via supply chain finance}

\subsection{Establishing upstream and downstream collaboration mechanism}

In the supply chain, the core enterprise and the marginal enterprise are integrated as a whole because the marginal enterprise makes much benefit from core enterprise's continuous expansion and development in sales promotion and production. Hence, the core enterprises should provide full support for the marginal enterprise development and maximize the competitiveness of the core enterprises. In briefly, when marginal companies and core companies in the same supply chain gain mutual benefit, both their overall competitiveness and operational efficiency of the supply chain will increase. At the same time, since commercial banks focus on serving the financial business of an efficient supply chain, they could ensure sustainable development by improving competitiveness and efficient operation.

\subsection{Strengthening the financial risk management of the supply chain}

For commercial banks to carry out financing business, both the operational efficiency of the supply chain, the credit level of core enterprises and the authenticity of trade with enterprises should be paid with equal attention. In addition, the implementation of agreements by companies with financing needs is limited by the operation of the supply chain, because the value of the supply chain output determines the source of funds for loan repayment. In addition, it is 
frequently examined whether the credit level of core enterprises meets the standards set by commercial banks so that the marginal enterprises could take the risks together with the core enterprises. Hence, it could be deducted that the effective development of supply chain financial services requires continuous improvement of the pre-lending credit review, because it is the basis for effective risk control after the business is launched.

\subsection{Actively developing online supply chain finance business}

Online seamless docking is crucial for all financing service platforms of financial institutions, enterprise e-commerce platforms, logistics supply chain management platforms of logistics enterprises, and financing settlement and payment platforms. One of the most important reasons is that the online communication of the supply chain finance business mainly depends on transforming the logistics, capital flow and information flow generated in the supply chain finance into online data. All those statistics will help with the improvement of business efficiency. In addition, in case an enterprise expects to reduce manual participation when performing supply chain business operations, a crucial task is to reduce the predictable risk and transaction cost. In that case, the enterprise needs to apply online supply chain financial services standards. Actually, only commercial banks actively develop online supply chain financial services so such banks can enable enterprises to obtain financing conveniently and quickly and obtain operating profits.

\subsection{Efficiently supervising the supply chain finance}

First of all, the bank designates relevant departments to clarify the legal rights and obligations of credit subjects, so that the supply chain financial services can be legally protected. Secondly, the financier management agency should always keep abreast of the development of the new financing model via regular specific research on its progress. Besides, it is necessary to apply relevant laws to avoid all illegal lending behavior so as to ensure the healthy and stable development of the financial market. Finally, the bank needs to establish the external supervision mechanism to ensure good control of the supply chain financial model and avoid illegal financing.

\section{Conclusion}

The emerging new financing model not only helps solve the financing problems of enterprises, but also enables enterprises to continuously improve their comprehensive capabilities in the development process. In addition, owing to the continuous development of the supply chain financial model, the problem of information asymmetry between the information obtained by commercial banks and that of the enterprises has also been effectively resolved. So it is necessary to pay more attention to the shortcomings of the current supply chain financial model. Effective measures should be taken to provide sufficient funds for the development of enterprises and achieve sustainable development.

\section{References}

1. Medders LA, Nicholson JE. Evaluating the Public Financing for Florida's Wind Risk. Risk Management and Insurance Review, 2019; 21.

2. Choutri SE, Djehiche B. Mean-field risk sensitive control and zero-sum games for Markov chains. 2018.

3. Turkulainen V, Swink ML. Supply Chain Personnel as Knowledge Resources for Innovation - A Contingency View. Journal of Supply Chain Management, 2017. 